\title{
Child sexual abuse material in child-centred institutions: situational crime prevention approaches
}

\author{
Tony Krone ${ }^{\mathrm{a}^{*}}$, Caroline Spiranovic ${ }^{\mathrm{b}}$, Jeremy Prichard ${ }^{\mathrm{b}}$, Paul Watters ${ }^{\mathrm{c}}$, Richard \\ Wortley $^{\mathrm{d}}$, Karen Gelb ${ }^{\mathrm{e} 1}$, Charlotte Hunn ${ }^{\mathrm{b}}$ \\ aSchool of Law \& Justice, University of Canberra, Bruce, Australia; bFaculty of Law, University of Tasmania, Hobart, Australia; \\ cDepartment of Comp. Science and Information Technology, La Trobe University, Bundoora, Australia; dDepartment of Security \& Crime \\ Science, University College London, London, England; eDepartment of Criminology, School of Social and Political Sciences, University of \\ Melbourne, Victoria, Australia
}

*Tony Krone (corresponding author): Associate Professor, School of Law, Faculty of Business, Government \& Law, University of Canberra, 11 Kirinari St, Bruce ACT 2617, T: +61-406378424, E: tony.krone@,canberra.edu.au, Orcid 0000-0001-63 62-7925

Caroline Spiranovic: Senior Research Fellow, Faculty of Law, College of Arts, Law and Education, University of Tasmania, Private Bag 89, Hobart, Tasmania, Australia 7001, Honorary Research Fellow, School of Population and Global Health, University of Western Australia, T: +61-36226-4847, E: caroline.spiranovic@utas.edu.au, Orcid 0000-0002-5270-8719

Jeremy Prichard: Associate Professor, Faculty of Law, College of Arts, Law and Education, University of Tasmania, Private Bag 89, Hobart 7001 TAS, T: +61-3-6226-2080, E: Jeremy.Prichard@utas.edu.au, Orcid 0000-0002-8481-7100

Paul A. Watters: Professor \& Program Director - Cybersecurity, Department of Comp. Science and Information Technology, School of Engineering and Mathematical Sciences, College of Science, Health and Engineering, La Trobe University, PS1 206, Bundoora, Victoria, Australia, 3083, T: +61-3-9479-3415, E: P.Watters@1atrobe.edu.au

Richard Wortley: Head, Department of Security \& Crime Science, Director, Jill Dando Institute of Security \& Crime Science, University College London. 35 Tavistock Square, London WC1H 9EZ, T: +44-(0)20-3108-3112, E: r.wortley@ucl.ac.uk

Karen Gelb: Consultant Criminologist; Lecturer, Department of Criminology, School of Social and Political Sciences, University of Melbourne, Victoria, Australia, 3010, T: +61-3-8344-6565, E: drkarengelb@gmail.com

Charlotte Hunn: Lecturer; Faculty of Law, College of Arts, Law and Education, University of Tasmania, Private Bag 89, Hobart 7001 TAS, T: +61-3-6226-2982, E:

charlotte.hunn@utas.edu.au 


\section{Child sexual abuse material in child-centred institutions: situational crime prevention approaches}

This paper focuses on the potential for child-centred institutions to use situational crime prevention (SCP) strategies to prevent or reduce child sexual abuse material (CSAM) ${ }^{2}$ offending as a distinct form of child sexual abuse (CSA). We discuss the failure of the Royal Commission into Institutional Responses to Child Sexual Abuse (RCIRCSA) in Australia to address the potential for CSAM offending to occur in child-centred institutions. Our premise is that CSAM offending is markedly shaped by the situation in which it occurs, rather than by any pre-existing preparedness to offend sexually against children. In this context, SCP for CSAM offending must be considered as part of overall strategies to combat CSA in institutional settings. However, we acknowledge that effective implementation of SCP in this area is not straightforward. We consider some of the challenges in implementing SCP at an institutional level.

Keywords: child sexual abuse material; institutional settings; situational crime prevention, responsibilities, obligations

Subject classification codes: include these here if the journal requires them

\footnotetext{
${ }^{2}$ We use the term child sexual abuse material as recommended by ICMEC (2018) throughout this paper in lieu of the terms child abuse material, child pornography, child exploitation material, child sexual exploitation material and indecent images of children. These terms have distinct meanings in different jurisdictions and broadly overlap in varying degrees with CSAM (Interagency Working Group on Sexual Exploitation of Children, 2016).
} 


\section{Introduction}

Situational crime prevention (SCP) seeks to prevent crime by addressing the opportunistic nature of criminal activity. This is achieved by targeting situational or environmental factors that facilitate a person committing a criminal act in terms of increasing the effort, increasing the risks, reducing the rewards, reducing provocations and removing excuses for potential offenders (Cornish \& Clarke, 2003; Smallbone \& Cale, 2016; Wortley, 2012; Wortley \& Smallbone, 2012). A closely related crime prevention framework is presented as a public health approach in which situational measures are arranged to target offenders, victims and situations at three levels of risk of offending, being the general population, at-risk individuals and known offenders/victims (Brantingham \& Faust, 1976; P. L. Brantingham, P. J. Brantingham, \& Taylor, 2005; McKillop, 2019; Quayle \& Koukopoulos, 2018; Van Dijk \& De Waard, 1991).

There is growing attention to the implementation of SCP strategies to limit CSAM offending. In large part, this is driven by the view that the scale and growth of the problem is beyond the capacity of traditional law enforcement to address. SCP strategies for CSAM initially were directed at high level interventions - with attention given more recently to developing techniques that could be implemented at an organisational level. In this paper we focus on the potential implementation of SCP strategies to combat online child sexual abuse material (CSAM) offending committed by adults in child-centred institutions. We acknowledge that there is a lack of evidence about CSAM offending in child-centred institutions. However, we argue that the well documented evidence of child-centred institutions systematically suppressing, hiding and denying CSA may explain the lack of evidence, and in any event, provides the justification for mandatory reporting of suspected CSAM offending along with the implementation of SCP strategies. We are concerned that attention given to CSA within child-centred institutional settings has overshadowed 
consideration of what could be done to combat CSAM offending and we seek to address that gap.

In launching its investigation into the internet and child sexual abuse the Independent Inquiry into Child Sexual Abuse in England and Wales said 'No issue is more pressing for contemporary child protection than the role of the internet in facilitating child sexual abuse' (Independent Inquiry into Child Sexual Abuse in England and Wales, 2019). The diversity and extent of online-facilitated CSA keeps growing as perpetrators exploit advances in technology in new ways (Wager et al., 2018) and the internet has created new spaces in which CSA offending may take place. At one end there is offline contact CSA where criminal activity is bounded in time and place and necessarily involves the physical presence of a child. At the other end there is non-contact CSAM offending that occurs online and indirectly involves children. As shown in Figure 1 there is an intersecting space where offline and online offending overlap and some of this offending has an element of engaging with children online, either as an end in itself, or for the purposes of facilitating contact CSA offline. 


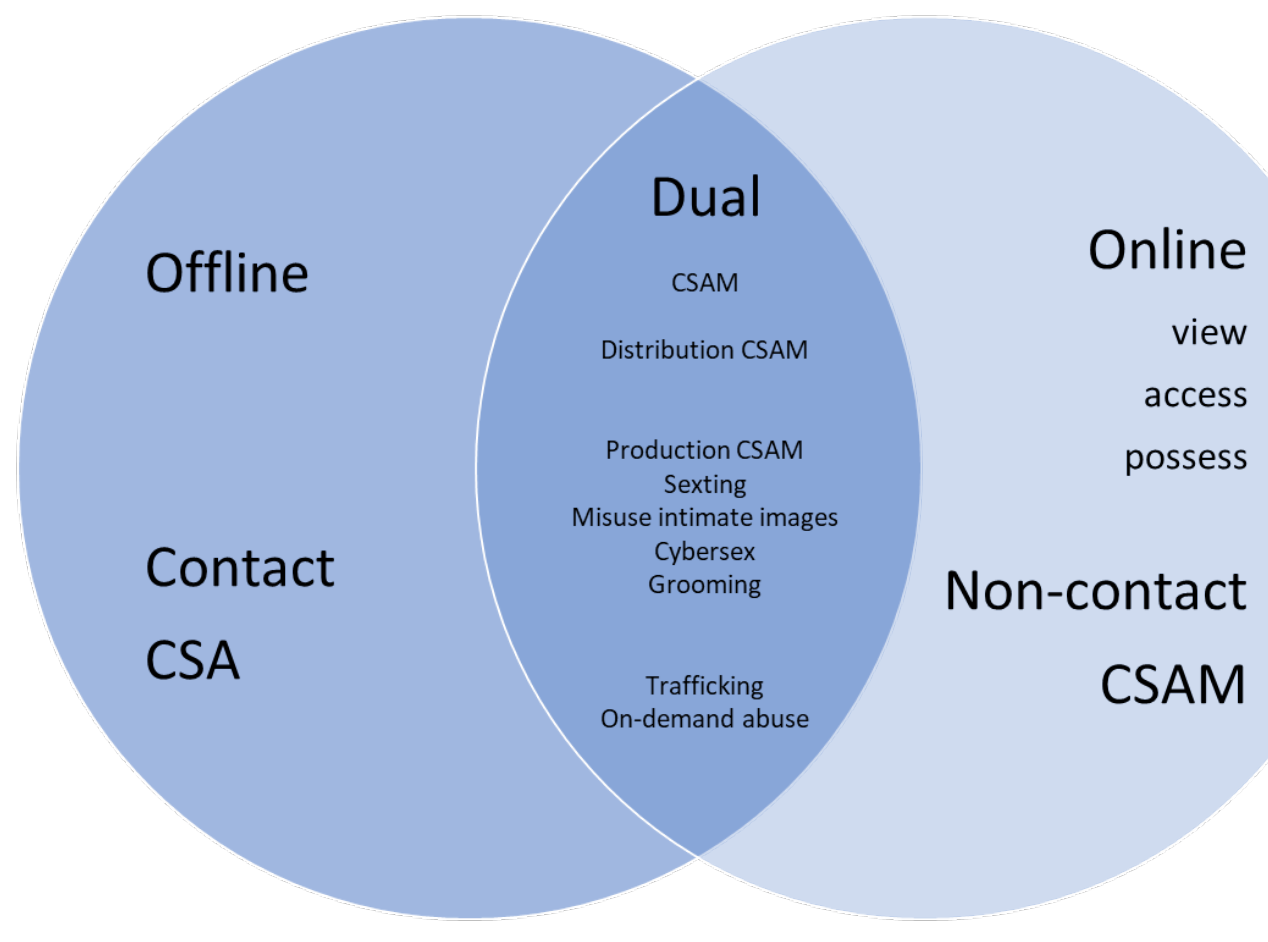

Figure 1: Intersection of off-line and online sexual offending involving children

Dual offending may involve a contact or an online offender intentionally interacting or intending to interact with a child by electronic means. This is the case with producing CSAM, on-demand live streaming of the physical sexual abuse of children, as well as online grooming of a child for sexual purposes. In relation to online grooming a distinction is sometimes made between contact-driven offenders seeking offline physical contact with children and fantasy-driven offenders seeking online interaction with children (Briggs, Simon, \& Simonsen, 2011; Chiu, Seigfried-Spellar, \& Ringenberg, 2018; Seigfried-Spellar et al., 2019). However, see also Broome, Izura, \& Lorenzo-Dus (2018) who argue that there is overlap between these categories. In any event, the reference to fantasy underplays the significance of an offender intentionally seeking interaction with a child - albeit in an online setting. 
Other forms of intentional online child interaction include where an offender solicits CSAM that has been self-produced by a child, or an offender exposes a child to adult pornography or CSAM - often as part of a sexual grooming process. With dual offending, a contact offender may additionally engage with any or all offences of viewing, accessing, possessing, distributing or producing CSAM and an online offender may be engaged in the production of CSAM which may involve physical interaction with children.

Within the wide range of CSA offending outlined in Figure 1, we address SCP strategies for CSAM offending in child centred institutions and our primary focus is specifically on non-contact offences of viewing, accessing or possessing CSAM. We begin by outlining the legal framework for criminalising CSAM, the nature and extent of CSAM, and the relationship of CSAM offending to other CSA offending.

\section{Part A: CSAM laws, CSAM content and CSAM offending in context}

\section{Obligations and legislation governing Child sexual abuse material}

The International Centre for Missing \& Exploited Children (ICMEC) sets out five key requirements for model CSAM laws. There must be legislation specific to CSAM, and the law must: include a definition of CSAM; capture technology facilitated offences; criminalise simple possession; and require ISP reporting. ICMEC reports that in 2018, of 196 Interpol member countries, 118 have laws that meet these minimum requirements (ICMEC, 2018). While there are numerous differences in the legal definition of CSAM, the core requirement taken from the Convention on Cybercrime is that the material depicts sexually explicit conduct being engaged in by a minor, or a person appearing to be a minor, or using realistic images representing a minor. This definition is expanded in the Optional Protocol on the Sale of Children, Child Prostitution and Child Pornography to include the representation or depiction of the sexual parts or sexual organs of a child for primarily sexual purposes. For a 
comprehensive discussion of relevant international instruments and the range of problems that have arisen in the definition of CSAM, see (Interagency Working Group on Sexual Exploitation of Children, 2016).

Laws regulating CSAM vary across jurisdictions in terms of the offender actions that are prohibited - which may involve possessing, accessing, producing, or distributing CSAM. Definitional issues include what is proscribed in terms of the age of persons depicted and the nature of what is depicted, tests of offensiveness and various defences, and the format of material that is prohibited (ICMEC, 2018). Within the same jurisdiction difficulties can arise in identifying CSAM due to differences between analysts (Kloess, Woodhams, Whittle, Grant, \& Hamilton-Giachritsis, 2019), or because of differences in classification schemes and known image datasets (Queensland Sentencing Advisory Council [QSAC], 2017).

A major point of difference in CSAM laws relates to age - with the Convention on Cybercrime stipulating that minor refers to all persons under 18 years of age - while allowing a lower age limit to be set of not less than 16 years. As indicated, definitions vary in terms of what is depicted, ranging from sexually explicit conduct with a child, the sexual organs of a child or combined images - whether real or virtual - where a child is portrayed in a sexualised context. Additional layers of complexity in defining CSAM may arise in relation to objective tests of whether a reasonable person would find material offensive - in the context of competing values of free speech and the availability of various defences - such as for material created for an artistic purpose. There may also be a subjective element based on the sexualisation of material by individual offenders (Krone, 2005). See for example, the decision by YouTube to disable comments on videos featuring minors to prevent predatory behaviour whereby paedophiles used comments to find, track and exploit children (YouTube, 2019). Definitions of CSAM may also vary in terms of whether they include cartoons, virtual material, morphed material, or material in written or aural formats (Al-Alosi, 2018). 


\section{The nature and extent of CSAM}

Where CSAM is the digital record of the sexual abuse of a child, engagement with that material is not a victimless crime (ICMEC, 2018). Various surveys give an indication of the nature and extent of the problem (Canadian Centre for Child Protection, 2016; International Association of Internet Hotlines, 2017; Internet Watch Foundation, 2017; Krieg, 2015; Seto, Buckman, Dwyer, \& Quayle, 2018) as summarised in Table 1. These surveys provide consistent findings regarding the high level of CSAM that involves prepubescent children (including infants) as well as the high proportion of severe forms of abuse depicted.

\begin{tabular}{|c|c|c|c|}
\hline Source & Sample characteristics & Age of victims & What is depicted \\
\hline $\begin{array}{l}\text { National Center } \\
\text { for Missing and } \\
\text { Exploited } \\
\text { Children } \\
\text { (NCMEC) } \\
\text { (Krieg, 2015) }\end{array}$ & $\begin{array}{l}\text { Identified child victim } \\
\text { database - images most } \\
\text { frequently reported }\end{array}$ & $\begin{array}{l}9 \% \text { infants and } \\
\text { toddlers } \\
64 \% \text { prepubescent } \\
27 \% \text { pubescent }\end{array}$ & $\begin{array}{l}44 \% \text { depicted oral } \\
\text { copulation } \\
52 \% \text { depicted anal and/or } \\
\text { vaginal penetration } \\
60 \% \text { manual stimulation } \\
11 \% \text { bondage and/or } \\
\text { sadomasochism } \\
11 \% \text { urination and/or } \\
\text { defecation }\end{array}$ \\
\hline $\begin{array}{l}\text { Cybertip.ca } \\
\text { (Canadian } \\
\text { Centre for Child } \\
\text { Protection, 2016) }\end{array}$ & $\begin{array}{l}\text { Reports by members of } \\
\text { the public and pro- } \\
\text { active searching by } \\
\text { analysts - } 152,000 \\
\text { reports between } 2008 \\
\text { and } 2016\end{array}$ & $78.3 \% 0-12$ years & $\begin{array}{l}50 \% \text { involved extreme } \\
\text { sexual assault (i.e., } \\
\text { bestiality, bondage, } \\
\text { torture) } \\
\text { where babies or toddlers } \\
\text { were depicted } 59.7 \% \text { of } \\
\text { abuse involved explicit } \\
\text { sexual activity }\end{array}$ \\
\hline $\begin{array}{l}\text { IWF } \\
\text { (Internet Watch } \\
\text { Foundation, } \\
\text { 2017) }\end{array}$ & $\begin{array}{l}\text { Reports by members of } \\
\text { the public and pro- } \\
\text { active searching by } \\
\text { analysts }\end{array}$ & $\begin{array}{l}55 \% 0-10 \text { years } \\
43 \% 11-15 \text { years }\end{array}$ & $\begin{array}{l}33 \% \text { involved sexual } \\
\text { activity between adults } \\
\text { and children including } \\
\text { rape or sexual torture }\end{array}$ \\
\hline $\begin{array}{l}\text { INHOPE } \\
\text { (International } \\
\text { Association of } \\
\text { Internet } \\
\text { Hotlines, 2017) }\end{array}$ & $\begin{array}{l}1.2 \text { million reported } \\
\text { child sexual abuse } \\
\text { images }\end{array}$ & $\begin{array}{l}3 \% 0-2 \text { years } \\
79 \% 3-13 \text { years } \\
18 \% 14-17 \text { years }\end{array}$ & $\begin{array}{l}\text { Not covered in the } 2017 \\
\text { report }\end{array}$ \\
\hline $\begin{array}{l}\text { NCMEC } \\
\text { (Seto, et. al., } \\
\text { 2018) }\end{array}$ & $\begin{array}{l}\text { Historical dataset of } \\
\text { traded images of known } \\
\text { victims 2002-2014 and } \\
\text { modern dataset of }\end{array}$ & $\begin{array}{l}\text { Modern dataset - } \\
\text { Actively traded } \\
\text { cases associated } \\
\text { with prepubescent }\end{array}$ & $\begin{array}{l}\text { Modern dataset - Actively } \\
\text { traded cases associated } \\
\text { with more egregious } \\
\text { content and more likely to }\end{array}$ \\
\hline
\end{tabular}




\begin{tabular}{|l|l|l|l|}
\hline & $\begin{array}{l}\text { traded images of known } \\
\text { victims 2011-2014 }\end{array}$ & children & $\begin{array}{l}\text { involve production by } \\
\text { family members }\end{array}$ \\
\hline
\end{tabular}

Table 1: Samples of detected CSAM - ages of victims and activities depicted

In 2018 EUROPOL reported that CSAM is detected in increasing amounts (EUROPOL, 2018). In Canada, Project Arachnid was set up in 2016 to detect CSAM and take action to have offending material taken down. As at July 2019, the project processed over 100,000 unique images per month, and since beginning it had processed more than 79 billion images. Of these, more than 10.2 million required analyst assessment leading to more than 4 million notices being sent to ISPs for take-down action (Canadian Centre for Child Protection, 2019). Other research - based on data from the National Center for Missing and Exploited Children (NCMEC) of content reported by the public and by sharing platforms in the period 1998-2017 - indicates there were over 23.4 million incidents or reports requiring investigation in that time and the pace of content creation and distribution is growing exponentially (with 9.6 million reports in 2017) and this is outstripping the capacity for manual review (Bursztein et al., 2019).

\section{CSAM offenders}

In the context of increasing demands being placed on scarce policing resources to combat CSAM offending, law enforcement efforts are prioritised according to the perceived risk to children posed by a CSAM offender who is an actual or potential contact CSA offender, or who has access to children, or who interacts with children online for sexual purposes (Long, Alison, Tejeiro, Hendricks, \& Giles, 2016). The process of filtering cases for investigation and prosecution means that CSAM offending and offenders are understood in relation to detected and prosecuted offenders providing information about the persistence of offending, but very little about at-risk individuals and the onset of offending (Seto, 2019). 
Information from cohorts of known CSAM offenders indicates they are heterogeneous (Brown \& Bricknell, 2018; Ly, Dwyer, \& Fedoroff, 2018) and research on the characteristics and motivations of CSAM offenders is described as 'sparse with inconsistency or uncertainty regarding definitions and samples' making it 'difficult to draw any meaningful conclusions' (Walker, Pillinger, \& Brown, 2018, p. 18). CSAM offenders are described in general as 'high functioning', 'pro-social individuals' with 'less extensive and diverse offending histories than contact offenders', they also 'display high levels of sexual pre-occupation, deviant sexual interests, and deficits in interpersonal and affective domains that surpass those of contact offenders' (Henshaw, Ogloff, \& Clough, 2017, p. 416). CSAM-only offenders have also been described as 'typically at a lower risk to reoffend with a contact sexual offence' than dual offenders (Babchishin, Merdian, Bartels, \& Perkins, 2018, p. 136; see also Merdian, Perkins, Dustagheer, \& Glorney, 2018; Merdian, Wilson, \& Boer, 2009).

\section{Situational factors in online non-contact CSAM offending}

CSAM offending predates the internet. In the US in the mid 1970's, mounting concern about the commercial availability of CSAM - in physical formats such as films and photographs led to the passing of the Protection of Children Against Sexual Exploitation Act in 1978 (18 U.S. Code s 2251-2253) which suppressed the sale and distribution of CSAM (Beranbaum et al., 1984). Research at the time indicated that contact CSA offenders and paedophiles with a pre-existing sexual interest in children engaged with physical CSAM and the US Customs Service and the US Postal Service played a primary role in detecting and prosecuting cases involving the physical distribution of CSAM (Belanger et al., 1984). However, the advent of the internet fundamentally altered the environment for CSAM offending. As Wortley (2012) observes, in 1982 the US General Accounting Office reported to Congress that commercially produced CSAM had declined and prosecution of CSAM was therefore not considered a high 
priority and then, less than a year later, 'the first standardised protocols for the internet were implemented and everything changed' (p. 188).

It is recognised that the proliferation of CSAM offending points to the importance of situational factors in the onset of offending, in contrast to the importance of dispositional factors involved in contact CSA (Taylor \& Quayle, 2008; Wortley, 2012; Wortley \& Smallbone, 2012). That is not to say that dispositional factors are not present, in fact, as argued by Seto (2019) the motivation for many CSAM offenders to engage in sexual behaviour with children is held in check by their self-control which fails in the online environment. Offenders may perceive that there is an absence of social regulation of online spaces which are believed to be beyond the gaze of others (Rimer, 2017), they may also perceive children online as not real and sexualised (Rimer, 2019).

The internet is described as criminogenic in fostering CSAM offending (Taylor \& Quayle, 2008). They consider that internet based CSAM offending cannot be explained entirely in terms of the sexual interests of offenders and that the general framework of inappropriate internet use can be usefully applied to understand this offending. Drawing on rational choice theory, they analysed the way in which CSAM may be accessed in an instant over the internet, very easily turning the precriminal situation of searching the internet into a criminal act. They conclude that accessing CSAM is influenced by the 'high affordance cues giving access to images', 'immediate and highly salient reinforcement on access to images', a perceived lack of 'capable guardianship and surveillance' and 'insensitivity to negative qualities' because of the combination of motivations and affordances (p. 124). See also (Quayle, 2012).

According to Wortley (2012), opportunity drives consumption of CSAM and the Internet is arguably a cause of CSAM offending. He presents a model of person-situation interaction that creates the conditions in which users develop an interest in children as sexual 
objects or lose the self-control to resist exploring such an interest that they have not otherwise acted on. This means that crimes can be prevented not only by reducing the opportunities for offending but also by addressing the situations or conditions which trigger, or are otherwise conducive to, criminal behavior.

\section{Part B: CSA and CSAM offending within institutions}

CSA offending occurring in an institutional context presents a grave threat to children. In recent years, numerous government inquiries, but most notably the Royal Commission into Institutional Responses to Child Sexual Abuse (the Royal Commission) in Australia, and the Independent Inquiry into Child Sexual Abuse in England and Wales, have highlighted the extent and severity of child sexual abuse in varied institutional settings (Wright, 2017). Understandably, a primary focus has been on contact CSA committed by persons in authority within institutions, the failure of those institutions to respond appropriately, and in many institutions, the aggravation of harm through their negative treatment of victims. Over an extended period, across numerous inquiries into child abuse in institutional settings, attention has shifted from individual offenders to highlighting the role of institutions in the perpetuation of abuse (Wright, 2017). The attribution of responsibility to institutions is summed up as 'bad barrel', rather than 'bad apple' recognising that the environment in many institutions had become criminogenic and fostered CSA offending (Death, 2015). As a result, there are increasing demands that institutions develop and implement crime prevention strategies to avoid CSA happening in the future (in addition to providing redress for past CSA).

There is limited evidence about the prevalence of CSAM offending in workplace settings, let alone, child-centred institutional contexts. It seems likely that there is considerable reluctance to report CSAM offending in the workplace. Given the systematic 
issues identified by the Royal Commission in relation to the non-reporting of CSA in childcentred institutions, it is highly probable that in the absence of compulsory requirements, instances of CSAM offending might be actively hidden. There is likely to be a hidden figure of workplace related CSAM offending because of a lack of IT systems for monitoring to detect this behaviour. Alternatively, CSAM may be detected but not reported to law enforcement for prosecution because of problems linking an event to a particular user, or concerns about the seizure or examination of workplace IT systems for evidence, or in an effort to avoid negative publicity.

In a US study of CSAM arrests in the period between 2000 and 2001 although most of the cohort (91 per cent) accessed CSAM from home, seven per cent accessed CSAM at work and two per cent accessed it at other places, such as libraries and schools (Wolak, Finkelhor, \& Mitchell, 2005). A series of cases in the US illustrate prosecutions for CSAM offending committed in government workplaces (Olson, 2004; Recupero, 2008). Other instances of CSAM offending in US workplace settings were revealed as defendants applied in subsequent criminal prosecutions to suppress the results of workplace searches or surveillance conducted without a warrant (Herbert, 2008; Hess, 2005). In Australian research it was reported that among a cohort of CSAM offenders, 13 percent had accessed CSAM online from their place of work (Krone et al., 2017).

In 2008, the Film and Publication Board of South Africa commissioned research on the knowledge and attitudes of South African employers and employees in relation to CSAM in the workplace (Plus 94 Research, 2008). Major findings were that only government departments were likely to treat CSAM incidents seriously and report them for criminal prosecution and that communication between senior management and human resource officers on this issue, was inadequate in all organisations. 


\section{Risk in child-centred institutional settings}

A report on CSAM in institutional contexts prepared for the Royal Commission reviewed the literature on CSAM offending and contact offending and concluded that CSAM only offenders posed a low risk for hands-on offending (Prichard \& Spiranovic, 2014). The authors also reviewed the literature on individual and situational risk factors influencing the onset of CSAM offending. They concluded that viewing CSAM may be a risk factor for hands-on CSA for vulnerable individuals already predisposed to sexual aggression and sexual deviancy. The review underlined the characterisation of CSAM offenders as 'ordinary mundane,' 'situational' offenders (p. 14).

In institutional settings there is a coincidence of two situations of risk in relation to CSA offending. The first is the access to children that is afforded to persons associated with the institution and the second is access to the online environment that is commonly made available in institutions. SCP strategies must therefore be devised to address the characteristics of each type of CSA offending. In this regard, online non-contact CSAM offending is likely to be most affected by SCP given that the person-situation interaction appears to strongly shape the emergence of this form of criminal behaviour. With the discovery of CSAM in an institutional setting, it is not possible at the outset to know whether the CSAM offender is also a contact offender, a dual offender, or an online non-contact CSAM offender. A precautionary approach requires investigation of possible contact or dual offending.

\section{RCIRCSA case studies}

The Royal Commission investigated responses to CSA in religious, government and nongovernment institutions across Australia using representative case studies for close examination (RCIRCSA, 2017a). Of the 57 published case studies, 24 investigated how 
particular organisations responded to CSA, 15 examined institutional policies, standards and legal issues, while 11 looked at the accounts of victims, and seven at offending by individuals within individual institutions. All the case studies were examined for references to CSAM offending and this was found in four of the eleven victim case studies and three of the seven offender case studies as indicated in Table 2.

\begin{tabular}{|c|c|c|}
\hline $\begin{array}{l}\text { CSAM } \\
\text { offending }\end{array}$ & Case study & $\begin{array}{l}\text { Relationship between CSAM offending and CSA } \\
\text { offending }\end{array}$ \\
\hline \multirow{6}{*}{$\begin{array}{l}\text { Produce } \\
\text { CSAM }\end{array}$} & \multirow{3}{*}{$\begin{array}{l}\text { No. } 9 \text { (Offender } \\
\text { study) } \\
\text { St Ann's Special } \\
\text { School }\end{array}$} & Active sex abuser in institution \\
\hline & & Producing CSAM using children in institution \\
\hline & & \\
\hline & \multirow{3}{*}{$\begin{array}{l}\text { No. } 37 \text { (Victim } \\
\text { study) } \\
\text { Centres for } \\
\text { Performing Arts }\end{array}$} & Active sex abuser in institution \\
\hline & & Producing CSAM using children in institution, using \\
\hline & & $\begin{array}{l}\text { CSAM to groom children, blackmailing children using } \\
\text { CSAM made of them }\end{array}$ \\
\hline \multirow[t]{3}{*}{ Grooming } & \multirow{3}{*}{$\begin{array}{l}\text { No. } 23 \text { (Offender } \\
\text { study) } \\
\text { Knox Grammar } \\
\text { School }\end{array}$} & Active sex abusers in institution \\
\hline & & Grooming children in institution using CSAM \\
\hline & & \\
\hline \multirow[t]{10}{*}{$\begin{array}{l}\text { Possess } \\
\text { CSAM }\end{array}$} & $\begin{array}{l}\text { No. } 1 \text { (Offender } \\
\text { study) } \\
\text { Stephen Larkins }\end{array}$ & $\begin{array}{l}\text { Falsified working with children clearance enables offender } \\
\text { with prior conviction for CSAM offending to be employed } \\
\text { by institution where he commits CSA }\end{array}$ \\
\hline & \multirow{3}{*}{$\begin{array}{l}\text { No. } 4 \text { (Victim } \\
\text { study) } \\
\text { The Towards } \\
\text { Healing Process }\end{array}$} & Active sex abuser in institution \\
\hline & & Possess CSAM after leaving institution \\
\hline & & \\
\hline & \multirow{3}{*}{$\begin{array}{l}\text { No. } 32 \text { (Victim } \\
\text { study) } \\
\text { Geelong } \\
\text { Grammar School }\end{array}$} & Active sex abusers in institution \\
\hline & & Possess CSAM in addition to being active sex abusers in \\
\hline & & institution \\
\hline & \multirow{3}{*}{$\begin{array}{l}\text { No. } 42 \text { (Victim } \\
\text { study) } \\
\text { Anglican Diocese } \\
\text { of Newcastle }\end{array}$} & Active sex abuser in institution \\
\hline & & Institutional failure to report possession of CSAM by \\
\hline & & priest prior to revelation of active sex abuse \\
\hline
\end{tabular}


Table 2 CSAM offending in case studies reported by the Royal Commission

\section{Producing CSAM}

In case study nine, an offender used children at an institution for moderately to severely intellectually disabled children to produce CSAM. Delays in investigation of this complaint and delays in reviewing seized material obscured the fact that images originally seized in 1991, but not fully investigated then, provided evidence of CSA committed by the offender. This material was later reviewed and used in 2002 to help secure convictions for those earlier sexual offences (RCIRCSA, 2015b).

In case study 37 , a dance-school teacher was being investigated in relation to CSA committed on multiple student victims including photographing students naked and engaging students in online grooming. The photographs were used to blackmail the students into further abuse and to prevent them from reporting the abuse. While the teacher was eventually found guilty on multiple counts of CSA, delays in obtaining a search warrant to seize his computer gave the offender time to dispose of it (RCIRCSA, 2017g).

\section{Grooming using CSAM}

In case study 23, five teachers at a boarding school committed acts of CSA and two of those teachers used CSAM to groom children in their care to commit sexual acts with them (RCIRCSA, 2016a).

\section{Possessing CSAM}

In case study one, an offender was employed by an institution after producing a falsified working with children clearance despite having a previous conviction for possession of CSAM. The offender went on to commit CSA within the institution (RCIRCSA, 2014). 
In case study 32, three teachers at a boarding school committed acts of CSA and of these, two were also convicted of possessing CSAM. One other teacher was convicted of filming up the skirts of female students (RCIRCSA, 2016b). The failure of church authorities to report the discovery of CSAM in the possession of Father Peter Rushton receives detailed attention in Case Study 42. The matter was not reported to police for investigation and Rushton was later found to be a long-term serial child sex offender (RCIRCSA, 2017h).

In case study four, a priest was removed from the priesthood following allegations that he had committed CSA, but without criminal charges being laid. He was later convicted of a CSAM possession offence occurring at a time subsequent to his removal (RCIRCSA, 2015c).

\section{Part C: Situational crime prevention}

\section{SCP strategies suggested for CSAM offending}

Concern over the growing prevalence of CSAM led to calls by a Parliamentary Committee in the UK for the private sector to do much more to address online child sexual abuse and take action in relation to CSAM (Home Affairs Committee, 2018). Several authors have considered the application of SCP to CSAM offending (Quayle \& Koukopoulos, 2018; Smallbone \& Cale, 2016; Taylor \& Quayle, 2008; Wortley, 2012; Wortley \& Smallbone, 2012). The main recommendations from these papers are summarised in Appendix 1. The recommendations range from the general form of what to do through to specific actions. Earlier recommendations, in the main, are largely high level and directed principally to centralised internet authorities such as Internet Service Providers (ISPs) or platform providers across four of the five guiding principles and associated actions of SCP as proposed by Cornish and Clarke (2003) and further elaborated by Freilich and Newman (2015). 
- Increasing offender effort (e.g. target hardening through educating children, filtering, blocking inappropriate sites and forums)

- Increasing risk (e.g. altering perceptions of surveillance, anonymity and the presence of law enforcement online)

- Decreasing rewards (e.g. removal of images) and

- Removing excuses (e.g. institutional policies and codes of conduct as well as automated messages).

The majority of the papers reviewed did not address the fifth guiding principle of SCP to reduce provocations with the associated actions: 'reduce frustrations and stress, avoid disputes, reduce emotional arousal, neutralise peer pressure and discourage imitation' (Freilich \& Newman, 2015, p. 214). A few of the recommendations are immediately applicable at an institutional level. Taylor and Quayle (2008) suggest several crime prevention strategies directed at the Internet industry, law enforcement, ISPs, peer to peer networks and hosting companies. Among these recommendations, the setting of strong and well publicised rules and instructions could be applied at an institutional level.

The SCP strategy for internet based CSAM offending proposed by Wortley (2012) builds on the situational prevention model (Clarke, 2008; Cornish \& Clarke, 2003, 2008) with opportunity reduction directed at reducing perceived rewards, increasing perceived effort and increasing perceived risks - the strategies of removing excuses and reducing provocations were excluded on the basis that they targeted offender motivation rather than the opportunity to offend. Wortley (2012) describes a role for ISPs to limit access to CSAM through site blocking or content filtering to reduce the rewards, ISPs could also increase the effort required through identity verification, regulation of peer to peer networks and blocking payments for CSAM. The perceived risks could be increased through high profile police 
operations, or police tracking and a suspect user warning system to heighten the perception that an offender may be detected.

Wortley and Smallbone (2012) argue that offenders who access CSAM are in many cases situational offenders - they are otherwise law abiding but the availability, accessibility, and anonymity afforded by the internet have created new opportunities and temptations. They propose situational interventions by different guardians/place managers (police, ISP providers, workplaces and parents) to prevent internet CSAM through increasing risk and effort, reducing rewards and provocations, and removing excuses. The workplace interventions include the use of filters, audits of internet use and codes of conduct for employees. The authors suggest targeting embedded CSAM and relapse prevention as examples of ways to reduce provocations.

Smallbone and Cale (2016) refer to the strategies proposed by Wortley and Smallbone (2012) and stress the importance of preventing offending before it occurs. They envisage a 'wide range of prevention agents' with 'a host of simple unobtrusive strategies that can be employed to make particular settings safer for everyone who encounters them rather than limiting the focus of prevention efforts to a small number of risky people' (p. 311).

Quayle and Koukopoulos (2018) present a range of strategies organised in terms of primary (pre-event), secondary (event) and tertiary (post-event) crime prevention in relation to host (children), vector (offenders), the physical environment (internet) and the social environment (norms/policies). This approach yields a comprehensive array of interventions as shown in Appendix 1 with internet monitoring, reporting mechanisms and chat moderation perhaps the most readily applicable at the institutional level. They also include counselling for those at risk of offending and treatment for those who have offended. 


\section{SCP and the Royal Commission}

The Royal Commission made 409 recommendations in its final report (RCIRCSA, 2017f) informed by a major research review provided to it on risk and protective factors for CSA in institutional contexts (Kaufman et al., 2016). The authors of that review rely on two theoretical perspectives to underpin the development of strategies to make institutions child safe. The first of these is the four preconditions model of contact CSA proposed by Finkelhor (1984). This holds that for an offender to commit physical child sexual assault four conditions must be present, namely, perpetrator motivation to commit CSA, the overcoming of perpetrator inhibition, the overcoming of external barriers, and the overcoming of victim resistance.

The second theoretical perspective is situational crime prevention (SCP), drawing on the work of Wortley and Smallbone (2006) which emphasises the importance of opportunities and environmental conditions in encouraging or permitting sexual abuse. The review also takes into account the interplay of victim and perpetrator characteristics within an institution along with situational 'institutional level' characteristics using a model developed by K. Kaufman, Tews, Schuett, \& Kaufman (2012, p. 13). The Royal Commission explicitly recommended a 'public health approach' to crime prevention (Clarke, Ribisl, \& Runyan, 2012; McKillop, 2019; Van Dijk \& De Waard, 1991). This is to be implemented across three levels of primary, secondary and tertiary prevention (RCIRCSA, 2017c).

\section{Institutional level SCP strategies for potential online-facilitated CSA offenders}

The Royal Commission recommendations for making institutions child safe are contained in three chapters (RCIRCSA, 2017c, 2017d, 2017e) and these are primarily directed at contact CSA and are stated in very general terms. Adapting the approach of Smallbone and Wortley (2017), Table 3 shows the Royal Commission recommendations for institution level 
interventions aimed at (potential) online CSA offenders mapped against the SCP principles of increasing effort, increasing risk and removing excuses. In the words of Freilich and Newman (2015) 'they say what to do, but they do not say how to do it' (p. 212). In this respect it must be noted that the recommendations are framed as part of a larger project to build capacity and collaborations to deal with the complexity of online crime. At the primary level, there is a general exhortation to minimise the opportunity for abuse to occur and to implement an esafety framework with codes of conduct and relevant policies backed up by staff training. At the secondary level, there is the provision of help-seeking services for adults or children at risk. At the tertiary level, there is the creation of centralised mechanisms for responding to, and escalating issues.

We canvas several more specific proposals for SCP aimed at potential online CSAM offenders at an institutional level adapting the matrix proposed by Smallbone and Wortley (2017) in Table 4. In so doing, we explicitly draw on, and seek to synthesise and expand the recommendations of the papers summarised in Appendix 1 - without repeating the arguments made in those papers for each recommendation. 